https://doi.org/10.29013/AJT-19-11.12-29-32

Lobova Elena Gennadievna, master student, D. Mendeleev University of Chemical Technology of Russia,

E-mail:promel14@gmail.com

Razheva Tatyana Mikhailovna, postgraduate student, D. Mendeleev University of Chemical Technology of Russia

Kurakov Vladimir Vasilievich, Candidate of Chemical Sciences, D. Mendeleev University of Chemical Technology of Russia Kuskov Andrei Nikolaevich, doctor of Chemical Sciences, D. Mendeleev University of Chemical Technology of Russia

\title{
STUDY OF THE CHARACTERISTICS OF CHITOSAN NANOGELS
}

Abstract. This work is devoted to the study of the basic physicochemical characteristics of new chitosan nanogels, namely, the determination of the degree of deacetylation, molecular weight, viscosity, particle size, and zeta potential of nanoparticles.

Keywords: chitosan, nanoparticles, gel.

Chitin is one of the most common biopolymers in the world, obtained on an industrial scale. As sources of chitin raw materials, the outer shells of various crustaceans, including crab and shrimp shells, can be used. Chitin deacetylation reaction produces chitosan - a substance that has great potential to be used as a basis for biomedical, pharmaceuti$\mathrm{cal}$, food and cosmetic products due to its biological compatibility and biodegradability [1].

Chitosan-based materials are used as delivery systems for biologically active and medicinal substances, and it is possible to create various forms of their introduction into the body, such as oral, nasal, parenteral and transdermal dosage forms, as well as biodegradable implants [2].

In addition, it was shown that chitosan has antiviral and antiphase activity; therefore, there are examples of its use in agriculture and food industry. The introduction of chitosan can reduce the growth rate of certain bacteria, infections, and also improves the protective functions of plants [3].

Due to the unique combination of chitosan properties, in recent years there has been growing interest in its use in the field of nanotechnology for the manufacture of a wide range of functional materials for the biomedical industry. For example, the development of liposomes coated for stabilization and protection of chitosan is known, which can be used in tissue engineering, drug delivery, wound healing, etc [4]. However, the niche for the use of chitosan nanoparticles in cosmetics is not yet occupied.

In the present study the main characteristic physicochemical parameters of chitosan were studied to understand the possibility of further application of these gels as the basis of cosmetic and pharmaceutical products.

The object of the study was chitosan produced by Pharm-Region LLC (Moscow), and hydrogels 
based on it. To prepare the gel a calculated amount of an aqueous suspension of modified chitosan was added to the beaker, then, constantly stirring, lactic acid was added dropwise, the reaction was stopped when the $\mathrm{pH}$ reached 5.2-5.6. The result was a clear gel with slight opalescence.

Chitosan is formed by N-deacetylation of a chitin molecule. The proportion of deacetylated units, defined as the degree of deacetylation (DD), usually rotates from 70 to $90 \%$. This parameter may vary depending on the source of chitin and processing methods. DD was evaluated for chitosan used in the work by using infrared spectroscopy (Nicolet 380 FT-IR), which resulted in $67 \pm 1.5$ wt.\% (Fig. 1).

An equally important parameter is the molecular weight (MW) of polymer. To determine the averageweight MW the viscometric method was used and the MM was $266 \pm 4 \mathrm{kDa}$.

The viscosity of the gels was measured on a Lamy Rheologe RM 200 instrument. The chitosan content's increasing in the gel correlates with the viscosity increasing (Fig. 2). It is also important to note the high thermal stability of gels containing chitosan over $1 \mathrm{wt} . \%$, as their structure remained stable when heated above $100^{\circ} \mathrm{C}$.

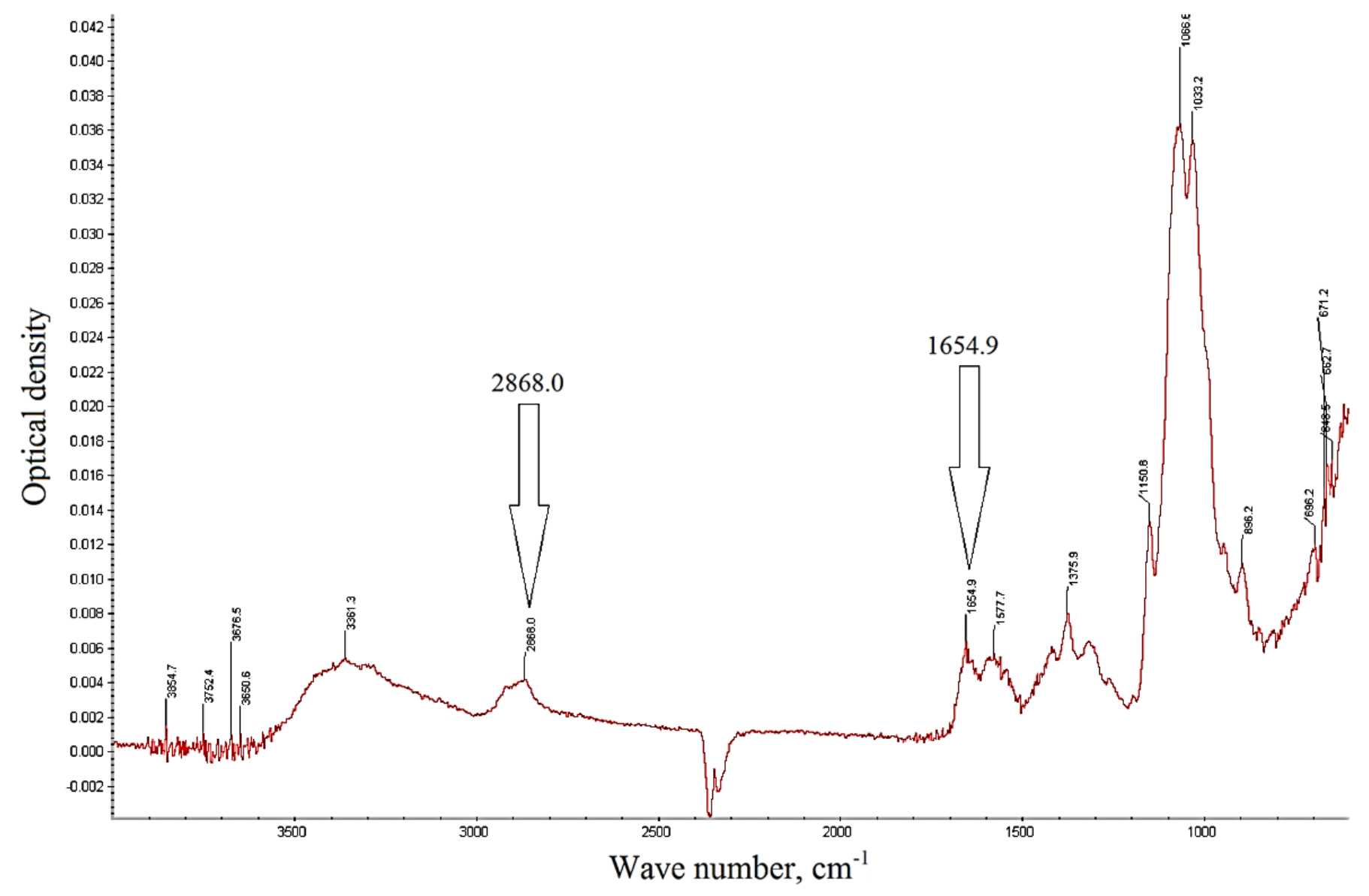

Figure 1. IR-spectrum of chitosan gel 


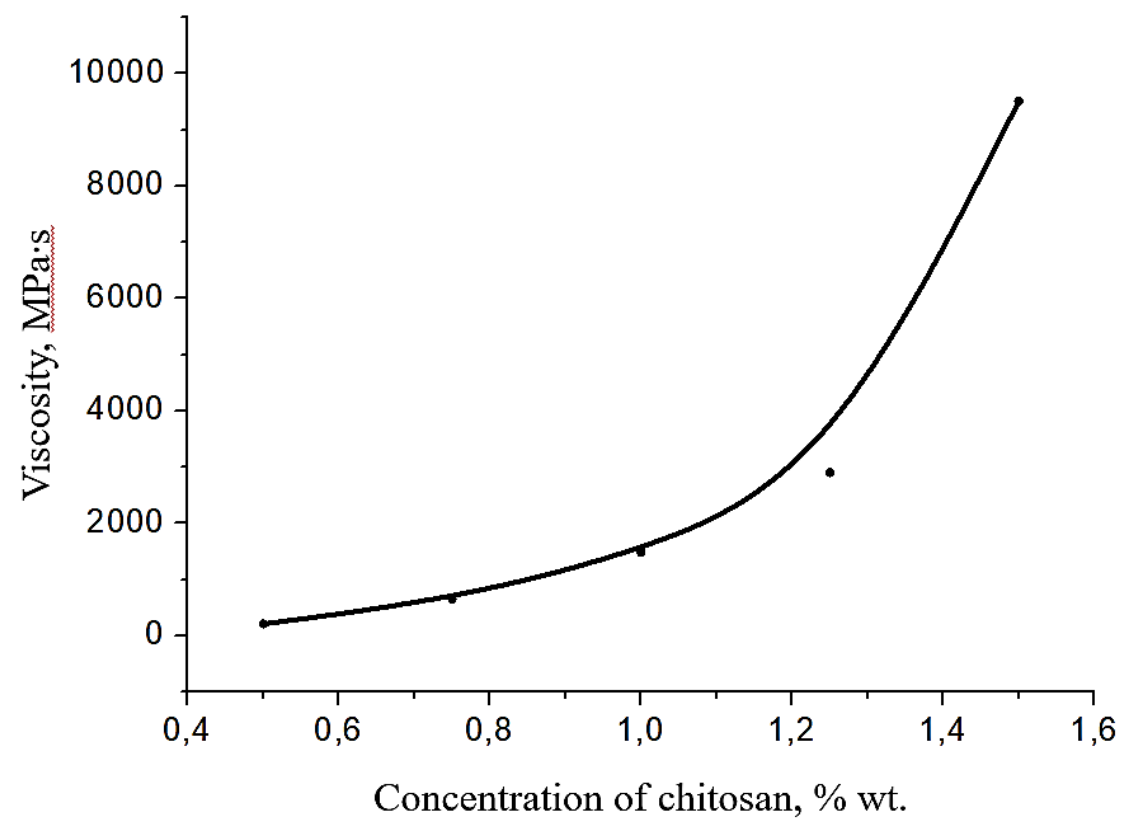

Figure 2. Viscosity curve of chitosan gels

The average diameter and zeta potential of the $\mathrm{nm}$ (Fig. 3). It is significant to mention that there resulted gels were determined using the Zetasizer Nano ZS-ZEN3600 particle size analyzer at $25^{\circ} \mathrm{C}$. were no larger aggregates in the system, which means The measured average particle diameter was $70-80$ that the structure obtained is quite stable. The particle surface charge is $25 \pm 3 \mathrm{mV}$.

\section{Size Distribution by Intensity}

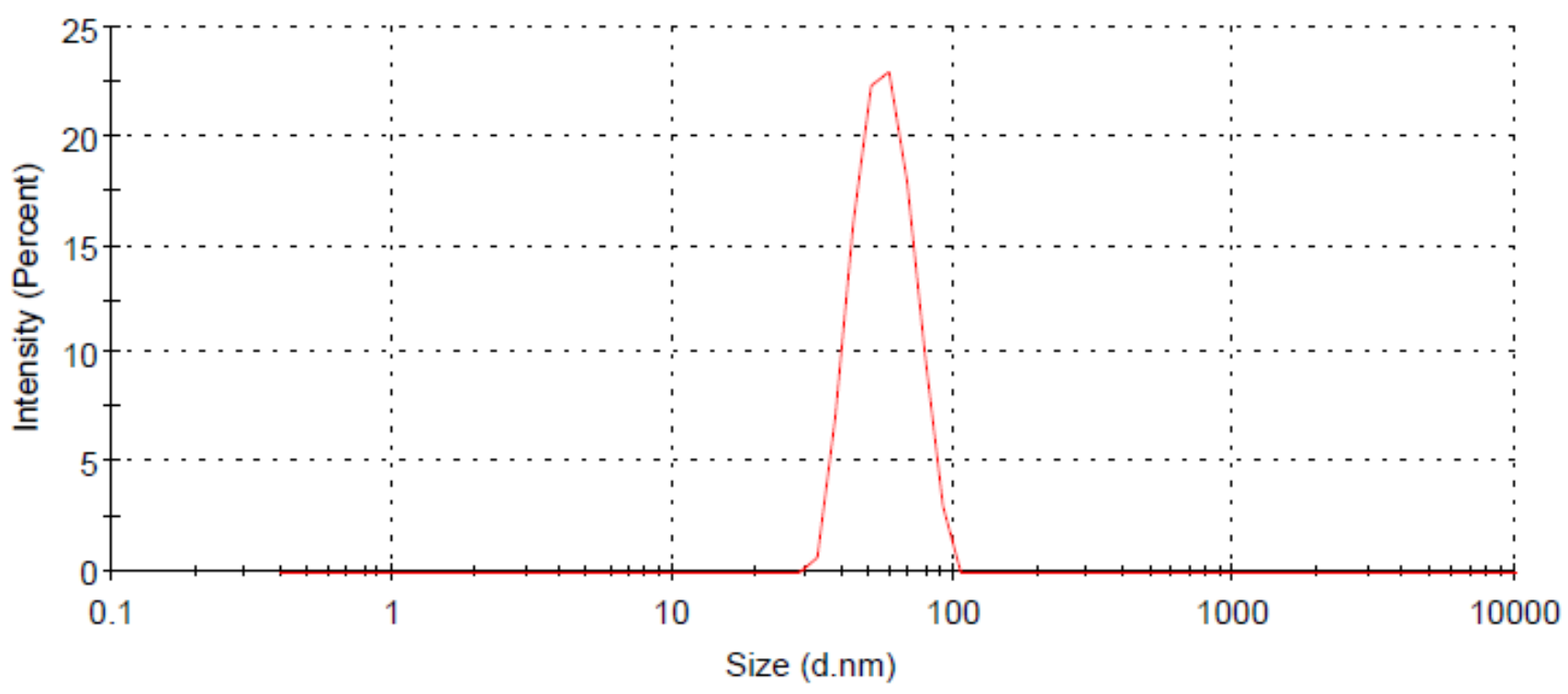

Figure 3. Chitosan gel particle size 
Since the purpose of the work is to develop the basis for cosmetics products from chitosan gels, it was necessary to evaluate the effectiveness of various preservatives for the developed gel systems. For this study we selected next preservatives variants: KemNat, KemNat $\beta$ and Stabil zero (Akema, Italy); Euxyl 903 (Shulke, Israel), Cosphaderm LA-T (Cosphatec,
Germany), Optiphen DLP (Ashland, USA). By the method of microbiological control of perfumery and cosmetic products, it was revealed that the preservative KemNat $\beta$ (1\%) showed the best effect in the sample of chitosan hydrogel, reducing the number of microorganisms by $93.7 \%$ within 7 days compared to the control sample without preservative (Fig. 4).

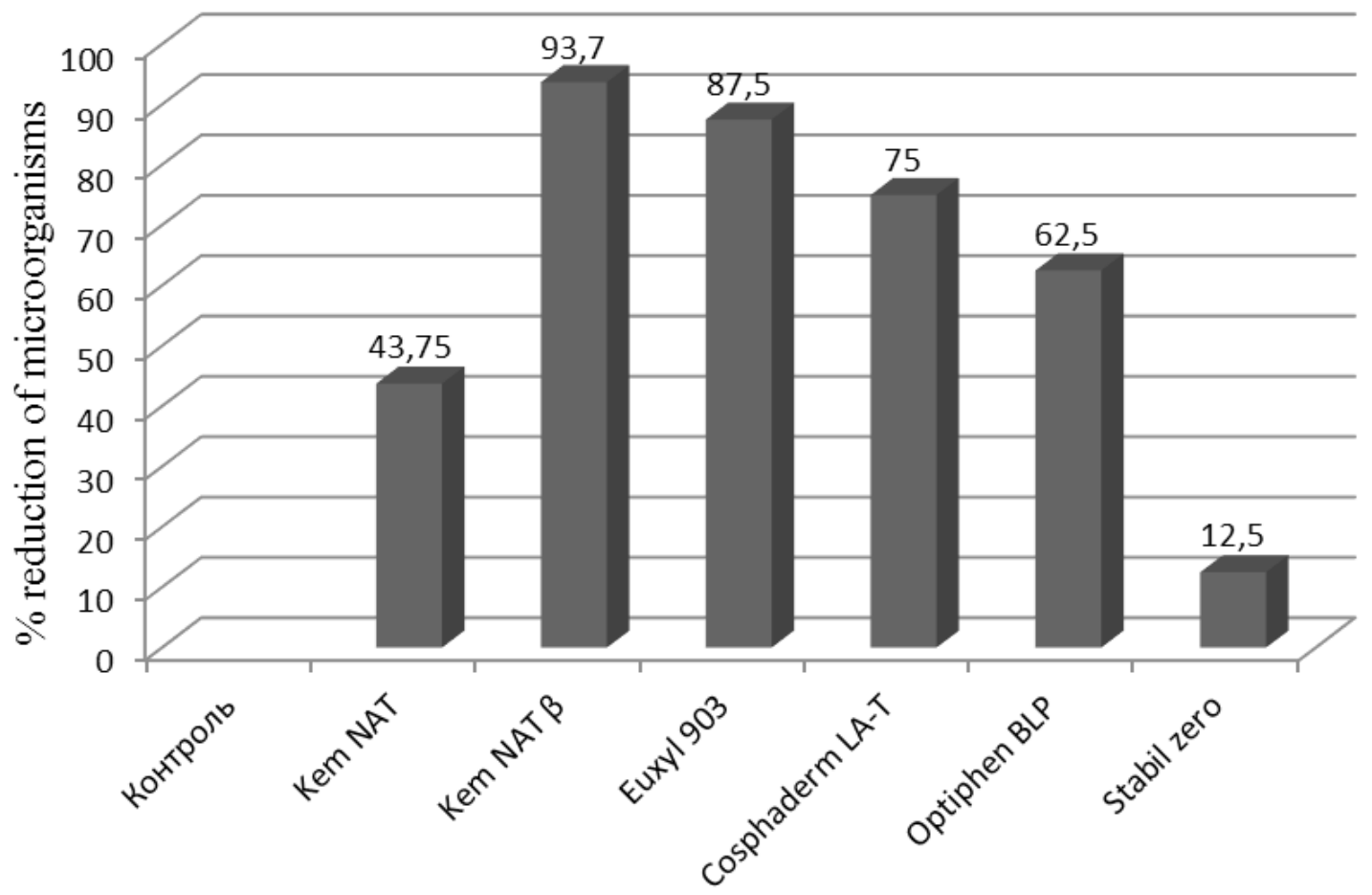

Figure 4. Preservative efficacy in chitosan gel samples.

Thus, today chitosan is widely used in the pharmaceutical and biological fields, while studies on the possibilities of its use in cosmetic products are less common. The results of the studies of the main physicochemical characteristics of the new nanostruc- tured chitosan gels presented in this paper showed good potential for their use, therefore, further development of cosmetic formulations based on the studied gels is planned.

\section{References:}

1. Anitha A., Sowmya S., Sudheesh Kumar P. T., Deepthi S., Chennazhi K. P., Ehrlich H., Tsurkan M., Jayakumar R. Chitin and chitosan in selected biomedical applications.- Prog. Polym. Sci., 2014 (39).P. $1644-1667$.

2. Auzely R., Rinaudo M. Controlled chemical modifications of chitosan characterization and investigation of original properties.- Macromol Biosci, 2003 (3).- P. 562-565.

3. Doares S. H., Syrovets T., Weiler E. W., Ryan C.A. Oligogalacturonides and chitosan activate plant defensive genes through the octadecanoid pathway.- Proc.Natl.Acad.Sci. 1995 (92).- P. 4095-8.

4. Ng W. L., Yeong W. Y., Naing W. Y. Polyelectrolyte gelatin-chitosan hydrogeloptimized for 3D bioprinting in skin tissue engineering.- Int. J. Bioprint, 2016(2).- P. 53-62. 